ANUARIO DE ESTUdios MEDIEVALES

48/1, enero-junio de 2018, pp. 331-360

ISSN 0066-5061

https://doi.org/10.3989/aem.2018.48.1.11

\title{
CIUDADES Y CONVENTOS FRANCISCANOS EN LA ANDALUCÍA BAJOMEDIEVAL. JERARQUÍAS URBANAS Y PROCESOS DE EXPANSIÓN DEL POBLAMIENTO*
}

\author{
TOWNS AND FRANCISCAN MONASTERIES IN ANDALUSIA \\ AT THE END OF THE MIDDLE AGES. URBAN HIERARCHIES AND \\ SETTLEMENT EXPANSION PROCESSES
}

\author{
JosÉ MARÍA MiURA ANDRADES \\ Universidad Pablo de Olavide \\ http//orcid.org/0000-0003-0891-5216
}

\begin{abstract}
Resumen: Uno de los elementos más frecuentes en el mundo urbano medieval eran los conventos de las órdenes mendicantes, los cuales se distribuyeron por diferentes puntos del plano urbano en función de diversos factores. A través del presente trabajo, analizamos cómo se produjo este proceso para los conventos pertenecientes a la Orden de Frailes Menores desde su implantación hasta 1520 tanto en la elección de los núcleos urbanos escogidos para su asentamiento, como en los diferentes ritmos de implantación y de los lugares en el interior de las poblaciones seleccionados. El artículo pone de manifiesto el profundo sello que los franciscanos, y especialmente sus conventos, han dejado en el urbanismo de Andalucía y del que a su vez son reflejo.
\end{abstract}

Palabras clave: órdenes mendicantes; Edad Media; Andalucía; franciscanos; urbanismo; conventos.

Abstract: One of the most frequent features of the medieval urban world was the monastic houses of the Mendicant Orders. They were distributed in different parts of the urban layout depending on several factors. The aim of this work is to analyse how this process occurred from its inception until 1520 as regards the towns chosen for their foundation. In addition, the different rhythms of establishment and the sites selected within the towns are studied. The article reveals the deep imprint that the Franciscans and especially their friaries have left in the urban layout of Andalusia.

Keywords: mendicant orders; Middle Ages; Andalusia; Franciscans; urban planning; monasteries.

\section{SUMARIO}

1. Introducción.- 2. La creación de los primeros conventos. Siglos XIII y XIV.- 3. La expansión del franciscanismo: reformistas y eremitas. Fines del siglo XIV y el siglo XV.- 4. El fin de la reforma y de la frontera: las fundaciones en Granada y la Banda Morisca y la provincia de Los Ángeles.- 5. Reflexiones finales.- 6. Bibliografía citada.

\footnotetext{
* Esta investigación ha sido propiciada por los proyectos del MINECO. "Construir la memoria de la ciudad: espacios, poderes e identidades en la Edad Media (siglos XII-XV)" (HAR2013-46388-R) y "Paisajes espirituales. Modelos de aproximación espacial a las transformaciones de la religiosidad femenina medieval en los reinos peninsulares (s. XIIXVI)" (HAR2014-52198-P).

Cómo citar este artículo: Miura Andrades, José María (2018), Ciudades y conventos franciscanos en la Andalucía bajomedieval. Jerarquías urbanas y procesos de expansión del poblamiento, "Anuario de Estudios Medievales" 48/1, pp. 331-360. https://doi.org/10.3989/aem.2018.48.1.11

Copyright: (C) 2018 CSIC. Este es un artículo de acceso abierto distribuido bajo los términos de la licencia de uso y distribución Creative Commons Reconocimiento 4.0 Internacional (CC BY 4.0).
} 


\section{INTRODUCCIÓN ${ }^{1}$}

Desde que a finales de los años sesenta algunos autores, especialmente tras el esfuerzo de Le Goff en su trabajo sobre el apostolado mendicante y el hecho urbano ${ }^{2}$, se plantearan una explicación de la ubicación de los conventos mendicantes dentro del esquema urbano, el estudio de los efectos de los asentamientos conventuales ha sido un referente en todo análisis de la evolución de las ciudades ${ }^{3}$. Los estudios sobre diversas regiones europeas se han reiterado a lo largo de los años ${ }^{4}$. Para el caso de Castilla la afirmación más frecuente lleva a aseverar que se situaron extramuros de las poblaciones y en sus arrabales ${ }^{5}$. También Jacques Le Goff anunció una posible vía de trabajo basada en la relación que se podía establecer entre el asentamiento de los conventos mendicantes y las puertas de las murallas de las ciudades ${ }^{6}$. Esta idea ha sido explorada por Graña Cid para el proceso castellano-manchego ${ }^{7}$.

En todos los casos se parte del hecho natural de la plasmación de una realidad social que genera establecimientos mendicantes. Pero, para Andalucía, esta afirmación carece de sentido. De hecho, creemos que hemos de invertir el argumento ya que la presencia mendicante en Andalucía, al menos en la primera centuria después de la conquista castellana, no es el resultado de un proceso natural sino de la imposición de un plan urbanístico. Es un proceso artificial.

La realidad de la Andalucía conquistada en el siglo XIII es la de la existencia de una vida urbana importante que dominaba y controlaba un amplio espacio y las actividades que se desarrollaban en el mismo. En esta Andalucía la adecuación del espacio a una sociedad estructurada para la guerra, donde los elementos de control del territorio priman sobre los de explotación del mismo, marcan la existencia de redes de poblamiento pensadas por y para una sociedad fronteriza y en continua expectativa bélica. Por ello, la labor repobladora inicial se centró en los grandes núcleos poblacionales, lo que reforzó el papel central de estos grandes centros urbanos ${ }^{8}$. Esta misma

\footnotetext{
${ }^{1}$ Abreviaturas utilizadas: ACS = Archivo de la Catedral de Sevilla; AGS = Archivo General de Simancas; AMJF = Archivo Municipal de Jerez de la Frontera; AMS = Archivo Municipal de Sevilla; APA = Archivo de la Provincia Andaluza franciscana; FHG = Fondo Histórico General; RGS = Registro General del Sello.

${ }^{2}$ Le Goff 1968.

${ }^{3}$ Caby 2012; Cuadrado 1996. Recientemente Viallet 2013.

${ }^{4}$ Buena prueba de ello en Bériou 2009; Gilomen 1995; Guidoni 1977.

${ }^{5}$ Álvarez 2014.

${ }^{6}$ Le Goff 1970.

${ }^{7}$ Graña 1993.

${ }^{8}$ Feria, Miura, Ruiz 2002.
} 
situación se reproducirá en el reino de Granada a fines del siglo XV. La ciudad es elemento indispensable del paisaje, núcleo de comunicación y centro de poder que domina un extenso alfoz. El fin de esta realidad, la de Andalucía como tierra de frontera, marca una evolución a lo largo del siglo XVI que reafirma las estructuras previas más que las transforma.

Si las ciudades son uno de los elementos esenciales de la articulación del espacio andaluz, existen elementos del paisaje urbano que atraen la atención antes que otros, que incluso no son percibidos. Por ello, la sociedad toma decisiones valorando más unos elementos del paisaje que otros (percepción diferencial). El paisaje urbano tiene un enorme valor semiótico, que Françoise Choay ha calificado de hipersignificante, ya que, sin necesidad de recurrir a sistemas verbales o gráficos de suplencia, es capaz de transmitir un mensaje ${ }^{9}$.

En una Andalucía que, desde el siglo XIII y hasta fines del siglo XV, nace y se reafirma como eminentemente urbana y cristiana en su sistema de valores, los elementos cristianos (iglesias, monasterios y conventos) necesariamente han de incidir con especial fuerza en la imagen y la percepción del espacio.

Se puede rastrear mediante la cartografía la importancia de la presencia de las instituciones religiosas en las ciudades andaluzas. Sin embargo, debemos tener presente que su valor simbólico es difícil de reconocer en horizontal ya que se materializa, con toda su intensidad, en la percepción en tres dimensiones. Las reconstrucciones de los contextos donde los "urbemas" o monemas urbanos (en este caso los conventos franciscanos) toman significado, se hacen imposibles ${ }^{10}$. Nos parece difícil restaurar, para cada periodo histórico, la volumetría de los conventos franciscanos pero es quimérico reconstruir el conjunto del caserío que los contextualiza.

Es nuestra intención acercarnos al proceso de transformación urbana que supone en Andalucía la implantación de los establecimientos franciscanos entre los siglos XIII y XVI.

\section{LA CREACIÓN DE LOS PRIMEROS CONVENTOS. SIGLOS XIII Y XIV}

Para Andalucía las primeras fundaciones franciscanas se van a llevar a cabo tras la ocupación de los centros urbanos e inmediatamente después de su conquista.

Fernando III dará lugar a la presencia de franciscanos en Córdoba y Sevilla. En Córdoba, próximo a los dominicos, surgía entre 1236-1240, en la

\footnotetext{
${ }^{9}$ Capel 1973; Choay 1972.

${ }^{10}$ Capel 1973, p. 112.
} 
collación de San Nicolás de la Ajerquía, el monasterio de San Pedro el Real de franciscanos ${ }^{11}$. Emplazado en unos entornos despoblados, frente a la muralla que separaba esta zona oriental de la Medina de la Villa, a lo largo de los siglos XIII y XIV, la comunidad de San Pedro el Real ampliaría su solar gracias a diversas donaciones de particulares y construirá su iglesia. Muy bien acogidos por la sociedad cordobesa, los alrededores se irían poblando durante los siguientes siglos, hasta que San Pedro el Real de Córdoba se convirtió en el centro neurálgico de un ámbito urbano que creció condicionado por su presencia $^{12}$.

De gran peso en la historia religiosa sevillana fue el convento Casa Grande de San Francisco, cabeza de la Custodia o provincia observante de Andalucía ${ }^{13}$. Fundado por Fernando III sabemos que, en 1252, estaba situado en la plaza de San Francisco, pues la eglesia de los Descalzos linda con el barrio genovés ${ }^{14}$. Este convento, ubicado junto a la plaza por él denominada de San Francisco, compartió sus muros con las nuevas Casas Consistoriales obra de Diego de Riaño en 1526. Tan céntrico emplazamiento fue factor decisivo para convertir al convento en un importante enclave urbano que bien pronto adquirió un gran protagonismo en la vida religiosa, social y cultural de la ciudad ${ }^{15}$.

Alfonso X, cuando completa la conquista de la Andalucía Bética con el valle del Guadalete y el reino de Niebla, tan sólo funda en Jerez el convento de franciscanos, no haciéndolo ni tan siquiera en la sede episcopal de Cádiz, aunque esta última se encarga de forma tradicional a un obispo minorita.

Sabemos que Alfonso X, en 1264, les concedió lugar en Jerez para edificar su convento frente a la Puerta Real ${ }^{16}$. A fines de siglo, fray Gonzalo, guardián de los frayres desçalzos de Xerez, presentaba a la tesorería del rey de Castilla Sancho IV una carta de pago de doscientos maravedíes ${ }^{17}$. El convento se encuentra extramuros, al igual que el de dominicos, lo que significa una cierta indefensión frente a los ataques de los musulmanes. Rápidamente se vincularon los franciscanos a los principales linajes de la ciudad que buscaron allí su enterramiento. Como más tarde analizaremos, en 1495 se procede a la traslación y donación de todos los bienes raíces y muebles del convento de San Francisco a los observantes de Madre de Dios de Jerez ${ }^{18}$.

${ }^{11}$ Escribano 1982; Olmedo 2012.

${ }^{12}$ Rodríguez, Hernández 2009.

${ }^{13}$ Medianero 1997.

${ }^{14}$ Archivio di Stato di Genova, cod. A, f. 281v., cod. C f. 448; ed. González Jiménez 1991, pp. 277-278.

${ }^{15}$ Castillo 1988; Marín 2013.

${ }^{16} 1264$, octubre, 9. Jerez. Ed. Mesa 1888, II, p. 408.

17 1294, noviembre, 30. AGS, Cuentas de Sancho IV, 30 de noviembre de 1294.

${ }^{18}$ 1495, marzo, 5. Jerez. Mesa 1888, p. 426. 
Además de las fundaciones ya expresadas hemos de añadir otras que, atribuidas a Fernando III, se nos muestran dudosas o incluso inexistentes. Toda fundación, por ser un proceso y no un hecho puntual, es difícil de datar. En las fundaciones de este periodo, a esta dificultad consustancial, se une el propio hecho de que el monarca que realiza la fundación es un santo: san Fernando. Llegará a la santidad oficial en el siglo XVII, periodo donde se está realizando la mayoría de las crónicas y anales de las órdenes, por lo que no es extraña la introducción de datos espurios en las historias conventuales con el fin de vincular la inicial fundación con Fernando III, dotando así a las mismas de un mayor grado dentro de la jerarquía religiosa local o de la Orden.

Las fundaciones de franciscanos en Baeza ${ }^{19}$ (que podemos situar entre 1301 y 1368 fecha en la que se trasladó al interior de la población), Úbeda ${ }^{20}$ (cuya edificación no aparece afianzada hasta inicios del siglo XIV), y Alcalá de Guadaíra ${ }^{21}$ (más una especulación pía) parecen claramente descartadas para este periodo.

El convento de san Francisco de Baeza debió de fundarse en la segunda mitad del siglo XIII. Quizás pudiera existir, tanto en Baeza como en Úbeda, un grupo de franciscanos pertenecientes a la efímera provincia de Berbería, desaparecida en $1239^{22}$, pero con una clara actividad misional. Los datos sobre San León de Baeza nos los aporta el cronista fray Alonso de Torres indicando su paso de extramuros al interior (San León) en 1373, de allí a San Antonio hasta mudarse al sitio que oy poseen el qual es el más principal de la Ciudad, y el más frecuentado de sus habitadores ${ }^{23}$. Sobre estas mudanzas volveremos más adelante.

El convento de San Francisco de Úbeda debió de fundarse antes de 1264 , año del que nos consta su primera escritura, retrasando algunos cronistas su erección al momento de la conquista. Con seguridad estaba fundado en 1368, cuando sufrió las razias de los granadinos, al igual que los conventos franciscanos de Baeza y Jaén ${ }^{24}$. El convento se construyó extramuros de la ciudad, entre las calles Rastro y Cava, lindando su huerto con las murallas de la ciudad en la collación de San Isidoro, junto a la segunda puerta de la ciudad en importancia, conocida como de Jaén o de San Francisco ${ }^{25}$.

\footnotetext{
${ }^{19}$ García Torralbo 2000.

${ }^{20}$ Almansa 2005.

${ }^{21}$ Miura 1994.

${ }^{22}$ Recio 1999.

${ }^{23}$ Torres 1683, p. 70.

${ }^{24}$ Sabemos de su existencia con anterioridad a esta fecha porque tras la razia acaecida en ella se solicita a los franciscanos de Jaén, Baeza y Úbeda que trasladen sus conventos intramuros. 1373, julio, 12. Aviñón. Almansa 2005.
}

${ }^{25}$ Ibidem, p. 193. 
El siglo XIV, salvo en sus dos últimos decenios, es una continuación de lo hasta aquí planteado. Las fundaciones son esporádicas, anómalas y responden más a impulsos personales que a estrategias de repoblación y consolidación de realidades urbanas. Parte de las fundaciones son llevadas a cabo por los linajes que conformarán la realidad política del Bajo Guadalquivir a lo largo de la Baja Edad Media en su proceso de afianzamiento en Andalucía. Para el caso de los franciscanos se realiza la erección de Moguer. Se trata, sin lugar a dudas, de una fundación compleja. Cuando en 1337 Alonso Jufre Tenorio y Elvira Álvarez fundan el convento de clarisas de Moguer nos consta que se establecen como capellanes de ellas frailes franciscanos ${ }^{26}$, quienes reciben de Lazarena Fernández la viña de Torrente ${ }^{27}$. En la documentación de Santa Clara, encontramos una última mención a los frailes franciscanos en la donación en 1356 del diezmo de la teja y el ladrillo de los hornos que son cerca de San Francis $\mathrm{CO}^{28}$, pero a partir de esta fecha, no hemos encontrado mención alguna de ellos. La fundación fracasó.

El 28 de marzo de 1344 Alfonso XI solemnizaba la toma de la ciudad de Algeciras con una procesión hasta la mezquita mayor, ahora purificada y consagrada como Iglesia de Santa María de la Palma ${ }^{29}$. Repitiendo los esquemas de Fernando III y Alfonso X y, ante la gran importancia estratégica de la nueva conquista, con el deseo de convertir a Algeciras en una gran urbe, procedió a la erección de una nueva diócesis, compartida con Cádiz, con su cabildo catedra ${ }^{30} \mathrm{y}$, lógicamente, se procedió al establecimiento de un convento franciscano. En 1345, Clemente VI autorizaba la fundación de un convento de franciscanos en las Algaidas de la Isla Verde (Insula Viridis) ${ }^{31}$. Poco más es lo que podemos saber de tal instituto, ya que los benimerines arrasaron y desolaron el lugar de Algeciras, y con ella el convento, en 1369. Algún autor ha apuntado la posibilidad de su traslado a Gibraltar ${ }^{32}$.

Una mención aparte merece la fundación de Jaén. El convento de San Francisco el Real de Jaén tiene su origen en el privilegio que el 12 de enero de 1354 signara Pedro I para dotarlo del terreno donde se establecen los franciscanos ${ }^{33}$. Se hace entrega a los franciscanos de una casa y capilla que, junto a un bosque y huerta, poseía la Corona desde la conquista de la

\footnotetext{
${ }^{26} 1348$, octubre, 31. Moguer. Vilaplana 1975, doc. 39.

${ }^{27}$ 1349, enero, 20. Moguer. Ibidem, doc. 42.

${ }^{28}$ 1356, mayo, 21. Moguer. Ibidem, doc. 55.

${ }^{29}$ García Fernández 1988.

${ }^{30}$ Mansilla 1957; Charlo, Piqueras 2007.

${ }^{31}$ 1345, abril, 20. Ed. Waddingo 1886-1933, pp. 659-660; Rubio 1953, p. 169.

${ }^{32}$ García Oro 1988,p. 429.

${ }^{33}$ Torres 1683, pp. 57-58.
} 
ciudad en un sitio cercano a la muralla, casi tangencial a ella, en el arrabal cercado de San Ildefonso, entre las Puertas de Santa María y de la Barrera ${ }^{34}$. El convento franciscano se convertirá en el eje de la expansión de la ciudad en dirección sur, hacia el arrabal de San Ildefonso. La plaza del Arrabal o de San Francisco acogerá el mercado y otros actos que no se podían llevar a cabo intramuros en la plaza de Santa María ${ }^{35}$.

Como no podía ser de otra manera, la presencia de los franciscanos en Córdoba, Sevilla y Jerez en siglo XIII responde a lo general de Andalucía. La monarquía tiende a realizar fundaciones religiosas inscritas en los procesos generales de repoblación y control del espacio conquistado. Por tanto, las funciones que las mismas desarrollan son las de dotar de servicios, en este caso religiosos, a los centros urbanos sobre los que la Corona de Castilla va a hacer bascular la defensa y organización del espacio tras el fracaso repoblador y la renuncia a la puesta en explotación del territorio. Se intenta reforzar el papel de centros de poder que permiten controlar la defensa de Andalucía.

Las fundaciones sólo se realizan en las principales ciudades que se sometieron a los cristianos mediante capitulación, no por pacto (lo que explica la inexistencia de conventos en Carmona, Écija o Niebla), y se encontraban vacías de población musulmana (Jaén, Úbeda, Baeza, Córdoba, Sevilla, Jerez de la Frontera y Algeciras). Además, dentro de ellas, permanecieron en un estado de formación embrionaria conventual no pudiendo considerarse conventos plenamente constituidos hasta la segunda mitad, en algunos casos muy avanzada, del siglo XIII e, incluso, inicios del XIV. El caso fracasado de Algeciras así como el de Jaén son endemismos residuales de estos procesos.

Los conventos franciscanos de los siglos XIII y XIV son fundaciones reales, lo que provoca la transmisión de la esencia monárquica al establecimiento real, que así adquiere un rango superior, traspasado por el fundador, sobre las otras fundaciones. Por ello, la misma se sacraliza ya que es el monarca, que es un "rey cristianísimo" -atributo que se caracteriza, además de por la lucha contra el infiel y la ejemplaridad de la vida religiosa del rey, por su protección a la Iglesia- ${ }^{36}$ el que la realiza.

Justamente por ser fundaciones reales tienden a ser monopolísticas. El monopolio real hay que estimarlo como resultado del afán de la monarquía por erigir instituciones para dotar a los centros urbanos de funcionalidad centralizadora, lo que generó tal excedente que se hizo innecesaria la

\footnotetext{
${ }^{34}$ Galera 1999.

${ }^{35}$ Rodríguez, Hernández 2009, p. 475

${ }^{36}$ Nieto 1988 , pp. 106-107.
} 
creación de nuevos establecimientos hasta algún tiempo después. También son las veteranas (veteranía que se transforma inmediatamente en jerarquía) de las existentes en su ámbito urbano o comarcal. Son, así, las futuras casas matrices de las posteriores fundaciones, los núcleos y centros de referencia de cualquier actuación de la Orden, convirtiéndose, en numerosos casos, en institutos de formación de religiosos o en residencias de los cargos y de la administración de cada orden.

Otro aspecto a tener en cuenta, tanto para estas fundaciones como para cualquier otra realizada en Andalucía, es la inexistencia de tensiones entre los franciscanos y el clero secular. Desde nuestra perspectiva, la carencia de conflicto procede de la ausencia de tiranteces entre las labores desempeñadas por el clero secular y el clero regular.

Con la creación de la diócesis de Sevilla se ponía de manifiesto una nueva estructuración de la Iglesia secular en Castilla ${ }^{37}$. El territorio diocesano no se dividía en arciprestazgos sino en vicarías. La propuesta se había aventurado tímidamente en Córdoba donde convivieron los arciprestazgos con las vicarías y donde cada vicaría agrupaba a un número indeterminado de parroquias urbanas y rurales con centro en un núcleo de población de importancia ${ }^{38}$. Al frente de la vicaría se encuentra el vicario, delegado permanente del obispo por un tiempo determinado por éste y con las competencias que libremente le concediera. Tampoco en las parroquias de Sevilla hubo beneficiados simples y un beneficiado cura o curero. En el arzobispado de Sevilla no hay más que un solo cura general de todo el arzobispado, que es el prelado ... y que tiene su título de cura en la Iglesia Catedral y no más ${ }^{39}$. Los beneficiados simples, económicamente bien dotados -con la única obligación de asistir a los actos de culto parroquial- no tenían el deber de la cura o cuidado pastoral. Pero ya no es solamente que no había curas párrocos, es que ningún clérigo quería serlo. El problema radicaba en la situación económica de los así llamados curas, quienes por no obtener rentas suficientes como tales curas son muy pobres y casi todos ellos idiotas y poco suficientes para el cargo que ocupan ${ }^{40}$.

La labor pastoral quedó en manos de las órdenes mendicantes y, especialmente, en la de los franciscanos por su mayor presencia en el territorio de Andalucía.

\footnotetext{
${ }^{37}$ Sánchez 2000.

${ }^{38}$ Sanz 1989, pp. 121-124.

${ }^{39}$ Sánchez 2000, p. 354.

${ }^{40}$ Ibidem, p. 355
} 


\section{LA EXPANSIÓN DEL FRANCISCANISMO: REFORMISTAS Y EREMITAS. FINES DEL SIGLO XIV Y EL SIGLO XV}

En la segunda mitad de la decimocuarta centuria, resultado del mayor arraigo de la población en el espacio, de la temprana salida de la crisis y del desarrollo del proceso autogenético reformador, se reinicia un ciclo fundacional que se mantendrá a lo largo del siglo XV. Es ahora cuando la creación y establecimiento de institutos franciscanos pudiera ser indicador de una fase natural de vinculación de la sociedad urbana y el movimiento mendicante, pero el mismo no se pudo plasmar en la ubicación de los conventos, ya que los elementos de reforma se vincularon al eremitismo y, por ende, a la búsqueda del desierto y el retiro de lo urbano. Surgen así procesos de reforma de las órdenes religiosas que se gestan enlazados con la realidad andaluza, al tiempo que nos indican una nueva religiosidad que lleva a la difusión de los grupos de terceros, beatas y eremitas, en todos los lugares, ciudades y villas ${ }^{41}$.

La mayoría de los claustros masculinos fundados durante los años finales del siglo XIV y la primera mitad del siglo XV optaron por la búsqueda de un retiro espiritual apartado de la ciudad.

En el caso de la ciudad de Córdoba lo hacen asentándose en la sierra cordobesa. Además del monasterio de San Jerónimo de Valparaíso y del convento de Santo Domingo de Escalaceli, se establecen los franciscanos en el convento de San Francisco de la Arruzafa. Fernando de Rueda donó todos sus bienes, entre ellos el sitio del convento, para erigir este eremitorio franciscano. Benedicto XIII, por su bula en 1414, les da las mismas facultades que al eremitorio de La Rábida ${ }^{42}$.

Para la urbe hispalense la fundación se realizó en una ermita llamada de Santa María de las Cuevas, en la margen derecha del Guadalquivir frente a la ciudad, donde en 1400 se establecerán los cartujos ${ }^{43}$. La creación de una Cartuja en 1400 supuso la firma de un acuerdo que llevó a estos terceros franciscanos a la cercana iglesia parroquial de San Juan de Aznalfarache así como a la ermita de San Juan de Morañina (en el actual término de Bollullos Par del Condado), con licencia para poner allí los frailes que quisieran. En 1409, Benedicto XIII encarga a Alfonso de Egea, gobernador del arzobispado hispalense, que confirmara la vinculación entre la parroquia de Haznalfaraig y los fratres penitentes III ordinis sancti Francisci, per Gundisalvum, archiepisco-

\footnotetext{
${ }^{41}$ Este movimiento y la información referida a los eremitorios y conventos hispalenses con mayor detalle, documentación y concreción en Miura 2014a.

${ }^{42}$ Rubio 1953, p. 264.

${ }^{43}$ 1400, enero, 16. Sevilla. ACS, FHG, leg. 114, doc. n. 7.
} 
pus Hispalensem, factam $^{44}$. En 1423 los terceros de San Juan de Aznalfarache se trasladan a otro lugar cercano bajo el nombre de San Sebastián ${ }^{45}$.

El convento de San Francisco del Monte estaba en Sierra Morena a una legua de la villa de Adamuz en un lugar en medio de un profundo valle. Martín Fernández de Andújar, platero y vecino de Córdoba, vivía de ermitaño en una posesión que tenía en Sierra Morena en el sitio llamado Benun Fart (Peña Tajada). Enrique III y Catalina de Lancáster ayudan a Martín a fundar un convento de franciscanos. Clemente VII el 6 de Mayo de 1394 autoriza la fundación ${ }^{46}$. En 1403 se trasladó a otro lugar cercano más benigno, lo que autorizó la bula de Benedicto XIII ${ }^{47}$.

Tenemos noticias de la existencia, algo dudosa, de un grupo de terciarios franciscanos en las inmediaciones de Osuna bajo la advocación de Sancti Spiritu en $1395^{48}$. Un año más tarde hay constancia de la presencia en la diócesis de Sevilla de un eremitorio conocido como Casafuerte. En 1403, la hay del de San Pedro de Benbex a una legua de Santa Eulalia de la Sierra en la cercanía de San Nicolás del Puerto. En el eremitorio de San Francisco del Monte, término actual de Villanueva del Río y Minas, vivía un tal fray Diego con seis compañeros, a los cuales Benedicto XIII concede, en 1417, iguales gracias que a los frailes de Santa María de La Rábida, otro de los eremitorios que a inicios del siglo XV se establecen en la diócesis de Sevilla, cercano a la población de Palos de la Frontera.

Existía en el lugar de las Veredas de Utrera una ermita donde con licencia del arzobispo de Sevilla en 1431 se asentaron los conventuales, quienes con limosnas edificaron un pequeño convento bastante falto de comodidades, dando lugar al convento de Nuestra Señora de las Veredas de Utrera ${ }^{49}$. Alfonso Rodríguez, bachiller en Derecho y vicario general del arzobispo de Sevilla Diego de Anaya, antes de 1420 había construido una ermita cerca de Marchena en honor de Santa Eulalia de Mérida, y ese año se la cede a fray Juan de Santa Marina, lector en teología en San Francisco de Córdoba a quien se lo confirma Martín V el año 1428. En 1406 existía otro eremitorio en Constantina. En la ermita de Nuestra Señora de la Bella en el pago de Torremarín, cerca de Lepe, por mediación de Francisco de Luján, se establecerán los franciscanos en $1430^{50}$.

\footnotetext{
${ }_{44}^{4}$ 1409, febrero, 2. Ed. Eubel 1898-1907, p. 163, n. 1172.

${ }^{45}$ 1400, enero, 16. Sevilla. ACS, FHG, leg. 114, doc. 7; Rubio 1953, p. 525.

${ }^{46}$ Ibidem, pp. 252-253. Fronchoso 2010, pp.180-181.

${ }^{47}$ Rubio 1953 , pp. 252-253.

${ }^{48}$ Sobre los eremitorios franciscanos sevillanos, Miura 2014a.

${ }^{49}$ Gonzaga 1587, p. 899; Rubio 1953 pp. 378-379.

${ }^{50}$ Miura 2014a, nos aporta la información de estos eremitorios sevillanos.
} 
El testigo portado por la monarquía durante los siglos XIII y XIV será transmitido a la alta nobleza y oficiales de corte que, a partir del cuatrocientos, adquieren un papel protagonista en la política fundacional, aunque la Corona nunca se desvinculará de la vida regular. Los condes de Santisteban inauguran este período, cuyo precedente tenemos en el fallido intento de Moguer, con la fundación del convento de San Francisco en la cabecera de su señorío. El convento de San Francisco de Santisteban del Puerto se debe a Diego Sánchez de Benavides, III señor de la villa y III caudillo mayor del reino de Jaén. Las obras del convento se iniciaron en los primeros años del siglo XV, no pudiéndose aportar la fecha exacta. Sabemos que ya existía en 1406. Dicho año Diego Sánchez manda, por su testamento, que mi cuerpo sea enterrado en mi convento de San Francisco que yo hice y edifiqué en mi villa de San Estevan. El convento pasó a ser panteón del linaje ${ }^{51}$. Un segundo convento giennense se erige en Beas de Segura, Vicaría dependiente de la Orden Militar de Santiago. En 1430 lo funda el Comendador Antonio de Valderrábano, siendo la primera casa de franciscanos en los dominios de la Orden de Santiago ${ }^{52}$.

La creación de institutos franciscanos en este periodo responde a dos realidades que hay que conjugar para analizar el fenómeno. Por un lado, el impulso reformador de la propia Iglesia castellana y de las distintas órdenes religiosas. Por otro, la realidad poblacional y económica de los núcleos poblados. Así se entiende que entre 1380 y 1430 se unieran a la nómina de lugares dotados de conventos Marchena, Utrera, Constantina, Adamuz, Villaverde del Río, Bollullos Par del Condado, Palos de la Frontera, Santisteban del Puerto y Beas de Segura, y que aumentara el número de establecimientos en los alrededores de las grandes poblaciones andaluzas, además de diversos intentos fallidos en la totalidad del territorio del Valle del Guadalquivir. Los reformadores franciscanos son responsables de gran parte de esta extensión del fenómeno al medio rural y a la periferia de las ciudades.

Después de 1430 los esfuerzos fundadores franciscanos se centrarán en las ciudades medias y en las cabeceras señoriales. La conquista de Antequera en 1410 supuso la reducción de la presión en las grandes ciudades cabeceras de los diversos sectores de la frontera. Por otro lado, el fracaso de la reforma ejemplarizante por la vía eremítica, que se constata desde mediados de la decimoquinta centuria, empujó a este enjambre de conventículos y oratorios franciscanos a trasladarse, o al menos intentarlo, al interior de las poblaciones. El caso de San Sebastián de Carmona puede ser un claro ejemplo del proceso ${ }^{53}$.

\footnotetext{
${ }^{51}$ Waddingo 1886-1933, IX, p. 396; Juliá 1972.

${ }^{52}$ Serrano 2009, p. 77.

${ }^{53}$ Miura 1998, pp. 212-213.
} 
Conocemos la existencia, antes de 1442, de un grupo de ermitaños, bajo la dirección de Pedro Cerezo, extramuros de Carmona (en las casas y lugares de Las Cuevas y Las Bastidas). En la cercana ermita de Santa María del Alcor, a dos millas de Carmona, existía otro grupo de eremitas bajo la tutela de fray Alonso de Palencia, franciscano observante. En 1447 fray Alonso es autorizado por Nicolás V, a petición de los regidores de Carmona, a trasladarse a la de Nuestra Señora de Gracia, más cerca (extramuros) de la ciudad. En 1461, Pío II confirma la fundación de un eremitorio de frailes menores de la observancia, quienes se trasladan desde Santa María de Gracia a una ermita dedicada a San Sebastián, extramuros de la ciudad pero junto al camino y cercano a la Puerta de Sevilla, dando lugar al convento franciscano observante de Carmona, que recoge a los diversos grupos eremitas anteriores.

Algo similar encontramos en Écija ${ }^{54}$. Es un claro ejemplo de las tensiones que, a partir de mediados del cuatrocientos, se producirán por las dificultades de trasladar los iniciales eremitorios, dispersos por el medio rural cercano a la ciudad pero extramuros, al interior del recinto murado. Sabemos de la existencia, por el testamento de Alfonso de Zayas, halconero mayor del rey, de un convento de franciscanos en Écija en 1449. En 1473 se trasladan desde una ermita, extramuros de la ciudad en la zona de la Puerta Cerrada, con advocación de San Gregorio, al interior de la ciudad. Como nos narra Gonzaga

originóse tal revuelo y alboroto tan grande que, azuzados, lo mismo la plebe que la mayor parte de la nobleza, por ciertos individuos de otra orden, los muros ya alzados a un tercio de su altura, fueron por el pueblo, poseídos de gran furia, derribados; y aún fue lo peor que indujeron al cabildo a desistir en absoluto de la obra ${ }^{55}$.

La fundación prosperó gracias al apoyo de algunos miembros pertenecientes a destacados linajes de la oligarquía concejil astigitana que incluso hicieron uso de las armas en defensa de los franciscanos.

Los Reyes Católicos dotaron en 1485 al convento con los bienes confiscados a García de Ávila y Alfonso de Baeza, vecinos de Écija, huidos al ser perseguidos por la Inquisición. Los bienes debían emplearse en acabar la construcción del edificio conventual y de los dormitorios y oficinas necesarias $^{56}$. La oligarquía local se encargó de completar y embellecer el convento ${ }^{57}$. Otra de las causas de tensión serán los intentos de sustitución de las sedes de los observantes por los grandes, veteranos y reales conventos

\footnotetext{
${ }^{54}$ Miura 1998, 213-215.

${ }^{55}$ Gonzaga 1587, la cita la tomamos de Rubio 1953, p. 396.

56 1485, abril, 11. Córdoba. AGS, RGS, enero 1485-diciembre 1486, doc. 689, f. 41.

${ }^{57}$ Hernández, Sancho, Collantes 1939, p. 313.
} 
conventuales. De hecho, la reforma franciscana en la segunda mitad del siglo XV arranca de la consolidación de la Familia de la Observancia o Regular Observancia. Se inicia la hora de la confrontación, pues el matiz dramático de la situación lo presentan las conquistas, casi siempre violentas, de los conventos urbanos de Castilla ${ }^{58}$. Para el mediodía castellano, aunque existieron tensiones a mediados del siglo XV (como en Córdoba en 1452, donde ciertos frailes que simulaban vivir en regular observancia se dedicaron a ofender, injuriar y agredir a los franciscanos conventuales) $)^{59}$, la situación no llegó a esos grados de violencia hasta el último cuarto del siglo XV. Para el caso de San Francisco Casa Grande de Sevilla conocemos las agitaciones entre claustrales y observantes ${ }^{60}$.

Todo parece indicar que en el caso de Jerez las convulsiones entre conventuales y observantes fueron de menor intensidad. Los inicios del eremitorio de Madre de Dios de Jerez nos son desconocidos. Algunos autores, guiados por la proliferación del fenómeno eremítico, o quizás mejor informados, no dudan en dar la fecha de los años iniciales del siglo XV como de su origen. Sin embargo, la primera noticia documentada del mismo es de mediados del siglo XV, cuando el cabildo de Jerez acuerda donarles dos lienzos de paño pardo por lo pobres que son ${ }^{61}$.

La única mención a tensiones entre conventuales y observantes en Jerez se producirá en 1483. En ese año, junto con los frailes de Santa María de Jesús de Sanlúcar de Barrameda:

Por quanto por los freyres de Santa María de la Madre de Dios desta cibdad es certificado que ay deferencia entre ellos e los del monesterio de San Francisco, e eso mismo todos los frayres descalzos de Sant Lucar, sobre la obediencia, e dis que sy no se remedyase a la cibdad verná cierto danno, mandaron que los señores Esteban de Villavicencio y Juan Riquel, veinte e quatro, e Fernando de Ferrera, jurado, entiendan en ello con los frayres de San Francisco e con el vicario, e dende e como ellos vean que se deue proveer asy lo fagan, para lo qual les dyeron poder complido ${ }^{62}$.

La transición hacia la Observancia se hizo fácil en San Francisco de Jerez. En 1495 se procede a la traslación y donación de todos los bienes raíces y muebles del convento de San Francisco a los observantes de la Custodia

\footnotetext{
${ }^{58}$ García Oro 1980, pp. 256-257.

${ }^{59}$ Rucquoi 1996, p. 74.

${ }^{60}$ 1480, septiembre, 18. Medina del Campo. AMS, Tumbo de los Reyes Católicos, doc. II, 73.

${ }^{61}$ Miura 2014b, pp. 569-570; Actas del Cabildo de Jerez. [Papel suelto] en Sancho 1945, p. 515 , nota 63 .

${ }^{62}$ 1483, agosto, 26. Jerez. AMJF, Actas Capitulares, año 1483, f. 196v. Sancho 1945, p. 522.
} 
de Sevilla ${ }^{63}$. Algunos días más tarde los observantes, representados por su Guardián, fray Juan Lucero, eligieron por patrono del convento al veinticuatro Francisco de Zúñiga ${ }^{64}$. La comunidad de Madre de Dios se traslada a San Francisco de Jerez y el convento es ocupado por clarisas de la Tercera Regla $y$, con ello, finaliza la existencia del segundo de los conventos franciscanos de Jerez.

Un proceso parecido será el que se lleve a cabo en San Antonio de Baeza. Inicialmente situado extramuros, posiblemente en el cerro más cercano a la Puerta de Úbeda, tras la razia de 1368 se trasladó a la capilla de San León, intramuros. En 1409 los franciscanos de Baeza se trasladan a la zona de El Ejido, extramuros, donde erigirán el convento de San Antonio. En 1493, una vez realizada la reforma del convento, los observantes lo abandonaron para trasladarse extramuros al convento de San Francisco que hoy permanece, dejando éste de San Antonio para un grupo de beatas que darán lugar al convento de clarisas de San Antonio ${ }^{65}$.

Junto con estos procesos de acercamiento entre las oligarquías nobiliarias, el interior de las poblaciones y el reformismo eremítico franciscano, la dinámica de fundar en la soledad del yermo y en las pequeñas poblaciones andaluzas continuó. Así se crean los conventos de Santa María de los Ángeles de Alcalá de Guadaíra, Santa María de Jesús de Sanlúcar de Barrameda y Nuestra Señora de los Remedios y San Rafael, también llamado convento Madre de Dios, extramuros de Córdoba.

La tradición atribuye la fundación del convento de Santa María de Los Ángeles de Alcalá de Guadaíra a Fernando III. Lo único cierto es que en el cabildo sevillano se presentó en 1443 una petición de ayuda por los frailes pobres de San Francisco, a quienes se les había donado un sitio para la construcción de una casa en Alcalá de Guadaíra, concediéndoles el concejo sevillano 2.000 maravedís de limosna ${ }^{66}$. Poco más es lo que sabemos del convento alcalareño. En 1524 aún era casa de la conventualidad. En 1525 pasó a la Observancia ${ }^{67}$. Fue el convento de Santa María de Jesús de Sanlúcar de Barrameda el primer establecimiento fundado en Andalucía perteneciente a la Vicaría de Canarias. Se trata de una fundación múltiple coetánea, bastante compleja. En 1440 Eugenio IV daba su licencia para que se pudiera fundar un convento que

${ }^{63}$ 1495, marzo, 5. Jerez. Mesa 1888, p. 426; Sancho 1945, pp. 493 y 515.

${ }^{64}$ 1495, marzo, 9. Jerez. Archivo del marqués de Campo Real, Fondo Suazo. Varios, antiguo n. 55. Sancho 1945, pp. 516-517.

${ }^{65}$ García Torralbo 2000 , pp. 29-30 y plano en p. 34.

${ }^{66}$ AMS, Actas Capitulares, 1443, noviembre, 13. 107, f. 24v. Palenzuela 1986.

${ }^{67} 1524$, julio, 15. Rubio 1953, p. 515. 
sirviera para el subsidio de los religiosos misioneros de Canarias ${ }^{68}$. En 1443, un grupo de vecinos de Sanlúcar hace donación y se comprometen a fabricar en una arboleda en los Barrancos de los Cañuelos una residencia para que pudieran morar fray Juan de Bilbao y fray Diego de Limpias y sus compañeros ${ }^{69}$. En 1443, encontrándose la edificación despoblada, fray Juan de Logroño tomó posesión de los bienes donados para fundar en ella un eremitorio de su orden, incorporado a las Misiones de Canarias ${ }^{70}$. La edificación conventual fue ganando fuerza a lo largo del tiempo.

Debemos citar el convento de Nuestra Señora de los Remedios y San Rafael, también llamado convento Madre de Dios de Córdoba. Perteneciente a la Orden Tercera de San Francisco fue fundado en 1440 por fray Rui Martínez de Pineda extramuros, en unos terrenos situados junto al arroyo de Pedroche, al noreste de la ciudad de Córdoba. No obstante, a principios del siglo XVII sería trasladado a un terreno en la collación de Santiago ${ }^{71}$.

La fundación del convento de San Francisco de Gibraltar es un claro precedente de lo que ocurrirá en los siguientes treinta años en los procesos de implantación de los franciscanos andaluces. Se trata de un convento apoyado por la nobleza titulada, que asume las funciones de la monarquía en los procesos de conquista y repoblación del territorio, al tiempo que fortalece lo que espera sea la ciudad cabeza de sus estados, dotándola de los símbolos de poder y fuerza del linaje, entre otros los eclesiales. El convento se fundó en 1471 pero no nos consta ni por quién, ni en función de qué documentación se da la información ${ }^{72}$. Sobre su fundación, cabe la posibilidad de que se llevara a cabo por los Guzmán, quienes en 1467 habían conquistado la ciudad y sometido a su señorío (usurpando funciones militares a la Corona y también las de fundaciones religiosas en nuevas ciudades conquistadas). Con la recuperación de la plaza por la Corona es probable que el establecimiento, no olvidemos que es de conventuales y no de observantes, fuera abandonado a su suerte por los posibles fundadores y la propia monarquía.

Siguiendo ese mismo esquema, en Belalcázar Elvira de Zúñiga, madre de fray Juan de la Puebla, decide fundar un convento de frailes observantes con la advocación de San Francisco de la Columna. Obtuvo bula de Sixto IV en 1474. El convento se situó a medio cuarto de legua hacia el este.

${ }^{6}$ 1440, agosto, 9. Florencia. APA, San Buenaventura, s. sig. Rubio 1953, pp. 374-375.

${ }^{69}$ ADMS, Leg. 4855. APA, Leg. Conv. de Sanlúcar. Copia legalizada de 1589. Moreno 1984, p. 158.

${ }^{70}$ 1443, septiembre, 21. Sanlúcar de Barrameda. APA, Leg. Conv. de Sanlúcar. Copia legalizada de 1589. Ortega 1915, pp. 123-132.

${ }^{71}$ Olmedo 2012, p. 35

${ }^{72}$ Waddingo 1886-1933, XIII, 1471, n. XXXIV, p. 474. 
Elvira de Zúñiga, viuda de Alonso de Sotomayor, residió en unas casas colindantes hasta su muerte en el año 1483. Tras ello, las hermanas de fray Juan de la Puebla decidieron crear un convento de clarisas. Lo hicieron en San Francisco de la Columna, que pasaría a denominarse Santa Clara de la Columna, y prometieron a los frailes la construcción de uno nuevo cerca de Belalcázar. El nuevo convento se fundó por Teresa Enríquez, viuda de Don Gutierre de Sotomayor, hermano de fray Juan de la Puebla, el año 1486. Se terminó su construcción en el año 1490, con la advocación de Los Santos Mártires de Marruecos. Alejandro VI expidió una Bula en 1493 por la que el convento pasó a la Custodia de los Ángeles ${ }^{73}$.

\section{EL FIN DE LA REFORMA Y DE LA FRONTERA: \\ LAS FUNDACIONES EN GRANADA Y LA BANDA MORISCA Y LA PROVINCIA DE LOS ÁNGELES}

Las dos últimas décadas del siglo XV son una prolongación de los dos movimientos reformistas. Uno lleva aparejada la fundación en el interior de las poblaciones y el otro la búsqueda del yermo.

Si el primer gran impulso fundacional franciscano en Andalucía vino de la mano del proceso de conquista y repoblación del territorio, un nuevo ciclo expansivo cristiano, esta vez hacia el reino de Granada, llevado a efecto entre 1485 y 1492, genera una segunda oleada fundacional con idénticas características, salvando las diferencias motivadas por las divergencias cronológicas, que la del siglo XIII. Se trata en ambos casos de un proceso de cristianización del territorio. Las fundaciones, todas ellas de franciscanos observantes ${ }^{74}$, se realizan en los núcleos más densamente poblados: Granada (San Francisco de la Alhambra) en 1492, Málaga (San Luis, obispo de Tolosa) en 1489, VélezMálaga (Santiago) en 1498, Almería (San Francisco) en 1491, Ronda (San Francisco) en 1490, Loja (San Francisco) en 1489, Baza (San Francisco) en 1490, y Guadix (San Francisco) en 1490. Tan sólo y como excepción se fundó en lugares menores. Es el caso del convento de San Luis de La Zubia, resultado de una promesa de la Reina Católica llevado a término en $1500^{75}$.

La voluntad de fundar arranca, en todos los casos, de la monarquía, sean directamente los reyes o algunos miembros de la casa real (caso de Baza), que monopoliza el establecimiento de las comunidades religiosas en el nue-

\footnotetext{
${ }^{73}$ Carrillo 2006.

${ }^{74}$ Toda la información sobre las fundaciones en el reino de Granada en Graña 1995, 1997.

${ }^{75}$ Rubio 1953, pp. 581-582.
} 
vo territorio. No hemos de olvidar la existencia del Patronato regio sobre el territorio del antiguo reino nazarí. Algunos de los conventos se establecieron provisionalmente en una primera ubicación para, en el caso de no ser adecuado y cómodo el lugar, trasladarse a otros puntos de la ciudad. En Ronda ocuparon inicialmente la futura parroquia del Espíritu Santo para trasladarse en 1490 a cien pasos al oriente del primitivo asentamiento. En Málaga, tras estar en un hospicio, se acabaron asentando en el arrabal, junto a la huerta del Comendador Mayor. En Loja se tardó bastante en la edificación por los diferentes traslados. Primero se les asignó sitio en lo que después será la iglesia de San Gabriel, pero no lo pudieron ocupar. Decidieron irse a las Peñuelas. Ante lo árido del sitio acabaron comprando un solar por encima de Los Caños en 1496, dando inicio la construcción del convento. En Guadix ocuparon un Carmen en el arrabal, un lugar cercano a la Puerta del Mar de la Musalla (Ciudad Conventual) en Almería y la antigua parroquia de Santiago en Vélez-Málaga.

La consolidación del dominio cristiano sobre el territorio andaluz en el siglo XVI, al hilo de su desarrollo económico y social vinculado a la puesta en explotación de la totalidad de la región tras la conquista del reino de Granada y al desarrollo del comercio atlántico, provocará una proliferación de manifestaciones físicas de este poder y del triunfo de la ortodoxia, que se han de concretar en monasterios y conventos distribuidos por el entramado urbano ya que, en numerosas ocasiones, los mismos se establecen sobre las antiguas casas de los fundadores.

Las abandonadas y peligrosas tierras de la Banda Morisca, muchas de ellas señorializadas ${ }^{76}$, ven nacer un número importante de conventos franciscanos en las principales cabeceras. En las prototípicas ciudades medias andaluzas, o agro-ciudades como las denominara López Ontiveros ${ }^{77}$, se repite el fenómeno de que las fundaciones más antiguas se establecen dentro de los recintos murados o en sus cercanías, mientras que las órdenes llegadas más tarde se emplazan en las zonas extramuros y lugares más llanos, aunque muchos de ellos acabarán abandonando su primitivo emplazamiento (en ocasiones ermitas) para trasladarse más cerca del centro de la población.

Tanto en la zona frontera del reino de Jaén como en la del reino de Córdoba, la aplicación de sistemas de control del espacio frontero encomendado a las órdenes militares en un primer momento y más tarde sustituido por la presencia de señoríos laicos -con una clara función de defensa frontera más que de colonizadores del espacio- hizo que, salvo una serie de puntos fortifi-

\footnotetext{
${ }^{76}$ Para los aspectos de conquista y repoblación del territorio bético (donde se incluye el reino de Jaén, el de Córdoba y el de Sevilla) son fundamentales los trabajos del profesor González Jiménez (González Jiménez 1985, 1988).

${ }^{77}$ López Ontiveros 1994.
} 
cados (a los que se les dotaba de una guarnición militar) y algunos enclaves aislados con un claro matiz y carácter militar, la mayor parte del territorio quedara desierto. Se hacía con ello (tanto por el carácter fronterizo -y por ende inseguro- como por la tipología del poblamiento generada) más que improbable la presencia de ninguna comunidad monástica o conventual en este amplio sector. De hecho, con anterioridad al siglo XV no conocemos ningún establecimiento regular en esta zona.

El sector fronterizo del reino sevillano, con iguales condicionantes que los aplicados para los de Córdoba y Jaén, condiciona la presencia religiosa. No se realiza ninguna fundación de un establecimiento conventual en tan extensa zona a lo largo de los siglos XIII y XIV. A fines del primer tercio del siglo XV, un grupo de franciscanos conventuales se establece cerca de Utrera y otro de observantes lo hace en Santa Eulalia de Marchena.

Tras esta inicial presencia, en una zona de retaguardia de la Banda Morisca, tendremos que esperar a inicios del siglo XVI para detectar las primeras iniciativas de establecerse en la zona más frontera de este sector por parte de los franciscanos. Debido a su carácter frontero durante la Baja Edad Media, la situación, desde el punto de vista demográfico y económico de la zona, no fue la más idónea para el asentamiento de las órdenes religiosas. Sin embargo, el ambiente de inseguridad, que llevaba aparejada la existencia de una débil población y una economía escasamente desarrollada, comienza a quebrarse en el primer cuarto del siglo XV, tras la conquista de Antequera por las tropas castellanas, y es inexistente tras el fin de la Guerra de Granada. En esos momentos, inicios del siglo XVI, las tierras fronteras se convierten en un auténtico polo de atracción de pobladores que buscan la puesta en explotación de las ricas tierras que conformaban el territorio, antes escasamente utilizadas ante la inseguridad y la peligrosidad de las incursiones granadinas. Y es precisamente tras esta fecha cuando se comienza un proceso de "colonización" religiosa por parte de las órdenes mendicantes y con especial intensidad por parte de los franciscanos.

El primer establecimiento del que tenemos noticias es el de Alcaudete. En 1500 Alonso Fernández de Córdoba, señor de la Casa de Montemayor, y su esposa María de Velasco, condesa de Siruela, realizaban una doble fundación en Alcaudete. La inicial pretensión era fundar un monasterio de clarisas y una vicaría de frailes para atender a las monjas, pero la vicaría se convertirá en convento bajo la advocación de San Francisco ${ }^{78}$. En ese mismo año se da inicio a la presencia franciscana en Antequera ${ }^{79}$, bajo la advocación de San Zoilo.

${ }^{78}$ Serrano 2006, p. 492

${ }^{79}$ Fernández 1943, p. 29. 
Los Reyes Católicos en 1500 dan licencia al concejo de Antequera para que ceda tierras a los franciscanos ${ }^{80}$, que fueron otorgadas, con una extensión de 700 varas, en $1502^{81}$. La fundación se justifica por la gran población de la ciudad $^{82}$. La construcción y dotación de ornamentos al convento continuó en los años siguientes ${ }^{83}$. En 1507 los reyes habían donado un total de 600.000 maravedís para la realización de diversas obras en el convento, de los que presentó cuentas el síndico ante el escribano del cabildo Álvaro de Oviedo en $1551^{84}$.

En Moguer, tras el fracaso de 1337, en 1504 Julio II concede licencia, a petición de Pedro Portocarrero, señor de Moguer y marqués de Villanueva del Fresno, para fundar un convento en el antiguo hospital del Corpus Christi de la villa de Moguer ${ }^{85}$. Esta fundación, aun así, debió de tardar algún tiempo en prosperar. Cuando Pedro Portocarrero otorga su testamento en 1519, no hay en él la más mínima mención al convento de Moguer, aunque hay importantes mandas y obligación de ciertas misas para otros conventos e instituciones religiosas ${ }^{86}$. Algo más tarde una comunidad de franciscanos dio origen al convento de San Antonio de Padua de Arcos en $1510^{87}$. Con limosnas de los vecinos de la población de Arcos, fray Antonio de Zamora el año 1508 levantó una ermita bajo la advocación de San Antonio de Padua, extramuros de la población, en un castañar situado cerca de la Puerta de Belén ${ }^{88}$. En 1510 Beatriz Pacheco, duquesa de Arcos, alzó un convento y lo dotó espléndidamente en su testamento ${ }^{89}$. El convento de Santa María de Jesús de Lebrija, perteneciente a la Venerable Orden Tercera Regular de San Francisco, es el resultado de una petición de los vecinos de la localidad, quienes, en 1510, solicitaron que se asentaran en la población con el apoyo del ayuntamiento de la villa ${ }^{90}$.

Los primeros marqueses de Priego comenzaron a construir en Montilla, cabecera de sus estados, un convento junto a su nueva residencia que edificaban en el "Llano de Palacio". El 3 de mayo de 1512 Pedro Fernández de Córdoba manda por su testamento construir un convento franciscano, que

\footnotetext{
${ }^{80} 1500$, septiembre, 18. Ibidem, p. 29.

${ }^{81} 1502$, junio, 10. Antequera. Ibidem.

${ }^{82}$ 1502, septiembre, 18. Granada. Alijo 1983, p. 95.

${ }^{83}$ 1504, [enero-marzo], Medina. AGS, Casa y Descargo, Leg. 4, f. 84.

${ }^{84}$ 1507, septiembre, 1. Fernández 1943, p. 30.

${ }^{85}$ 1504, agosto, 7. Roma. Waddingo 1886-1933, XV, n. XII, p. 620.

${ }^{86} 1519$, julio, 27. Jerez, cerca de Badajoz. Archivo de la Diputación de Huelva, González Gómez 1977, pp. 284-301.

${ }^{87}$ Cuevas, Cuevas 1985, p. 103.

${ }^{88}$ Ibidem.

${ }^{89}$ Carriazo 2004, pp. 274-275.

${ }^{90}$ López 1989, p. 92.
} 
acaba fundándose en 1515, y ser enterrado en él. A partir de ese momento pasa a convertirse en panteón familiar de los marqueses de Priego. Su hija, María Jesús de Luna, quiso instituir un convento de clarisas. El convento que en un principio iba destinado a acoger frailes franciscanos será ocupado en 1525 por las clarisas. Los franciscanos trasladaron el convento a la Huerta del Adalid, a una legua de distancia del núcleo urbano, y tomó la advocación de San Lorenzo. En la localidad que da nombre a los estados, Priego de Córdoba, hacia 1515, Pedro Fernández de Córdoba acometió la tarea de edificar un convento situado en un extremo del interior de la villa, junto a las murallas, aunque dentro de la cerca, con la advocación de San Esteban ${ }^{91}$.

En 1514 en Andújar, en el espacio de Santa Ana, abandonado por las clarisas, se instalaron los franciscanos formando una vicaría que no llegó a convento. Algunos años más tarde dejaron el antiguo convento de Santa Ana para establecerse en la populosa calle Ollerías ${ }^{92}$. Aun cuando la mayoría de los autores da una fecha más tardía, lo cierto es que el convento de San Francisco de El Puerto de Santa María es fundación de Luis de La Cerda, duque de Medinaceli, en 1517, sobre la antigua ermita de Santa Brígida ${ }^{93}$. En Antequera vamos a encontrar a un grupo de ermitaños franciscanos que en 1518 estaban establecidos en un lugar entre el Cañuelo y Entreárboles, a unos tres cuartos de legua de la ciudad, bajo el nombre de Las Suertes. En 1607, se trasladarán al interior de la población bajo la advocación de Nuestra Señora de los Remedios ${ }^{94}$. Un fracaso de fundación franciscana nos es conocido para Cádiz. Se trata de los intentos que, en 1516, llevó a término el conventual fray Francisco Aznar para instituir un convento $0^{95}$.

Como hemos comprobado, los primeros años del siglo XVI vieron una eclosión de fundaciones franciscanas en los territorios limítrofes con el reino de Granada y una activación de la costa atlántica andaluza. Sin embargo, tal crecimiento monástico y conventual no afectó a las tierras de la Banda Morisca bajo el señorío jurisdiccional o antiguo señorío de las órdenes militares.

En nuestro ámbito de estudio esta inexistencia de conventos no puede explicarse si no es por su dependencia señorial a unas órdenes militares, las de Santiago, Calatrava y Alcántara, que se mostraban reacias a la intromisión de otras instituciones religiosas en las labores de asistencia espiritual y control de los fieles.

\footnotetext{
${ }^{91}$ Peláez 2003.

${ }^{92}$ Serrano 2006, p. 490.

${ }_{93}^{93}$ Waddingo 1886-1933, XVI, 1517, n. LI, p. 66.

${ }^{94}$ Fernández 1943, pp. 63-64.

${ }^{95}$ AGS, Cámara de Castilla, leg. 121.222 y 125.99. Sánchez 1981, pp. 222-223.
} 
A inicios del siglo XVI el franciscanismo prácticamente ha terminado la reforma en Andalucía, donde quedan algunas casas para los claustrales (Jaén, Gibraltar y Alcalá de Guadaíra). En el proceso de sustitución de unas comunidades, los claustrales, por otra, los observantes, también se produjo un abandono de la vida eremítica y una nueva mayor vinculación de la orden al medio urbano. Tal es el caso, ya analizado, de Madre de Dios de Jerez de la Frontera, que se trasladó a San Francisco el Real en $1495^{96}$. Santa María de Jesús de Sanlúcar de Barrameda también se traslada al interior de la población por estas mismas fechas ${ }^{97}$, Nuestra Señora de las Veredas de Utrera en 1524 se reubica en el interior de la población por el testamento de Lope Ponce de León ${ }^{98}$ y Nuestra Señora de la Bella de Lepe, refundado por Francisco de Zúñiga y su mujer doña Leonor Manrique, hará lo mismo en $1513^{99}$.

Sin embargo, lo inacabado del proceso reformador o, mejor, la continuada presencia de un franciscanismo radical en su concepción de la pobreza y su aspiración a la perfección en el mantenimiento de la regla, generó o mantuvo (depende de cómo entendamos la reforma franciscana cisneriana) corrientes de espiritualidad franciscana que buscan en lo eremítico su forma de expresión y que se encontrarán con la oposición de los observantes. La presencia del eremitismo franciscano continuó en Andalucía de la mano de los conventos y las fundaciones de los angelinos en Sierra Morena.

Fray Juan de la Puebla determina unas nuevas condiciones de ubicación para los cenobios angelinos ${ }^{100}$. En su estricta observancia de la regla de san Francisco, defendía la erección de conventos aislados de las poblaciones. Esta peculiaridad se explica por la necesidad de que los religiosos estuvieran en perfectas condiciones de aislamiento espiritual, además de poder atender al pueblo en sus dolencias espirituales.

La primera de las fundaciones es la de Santa María de los Ángeles. Podemos considerar que el 14 de abril de 1490 el convento está constituido. Hasta 1520 se erigieron en Andalucía nueve conventos dependientes de la Custodia, en 1517 provincia, de Los Ángeles. Se trata de San Luis del Monte, situado a unos seis kilómetros de Palma del Río, en 1492 o 1493 , San Jerónimo de Cazalla de la Sierra en 1493, Nuestra Señora de la Piedad de Guadalcanal en 1495, San Alberto del Monte en Santa Eufemia en 1504, San Francisco de Pedroche, más tarde Nuestra Señora del Socorro, en 1510,

${ }^{96} 1495$, marzo, 5. Jerez. Mesa 1888, p. 426.

${ }^{97}$ Moreno 1984, p. 158.

${ }^{98}$ Rubio 1953, p. 379.

${ }^{99}$ Ortega 1986, I, p. 350.

${ }^{100}$ Para estas fundaciones contamos con una abundante bibliografía. De carácter general: Guadalupe 1662; Carrillo 2006; Santiago 1999; Hernández González 2006. 
San Antonio de Padua de Chillón en esas mismas fechas. En 1518 por iniciativa de los primeros condes de Palma se crea el de Nuestra Señora de Belén de Palma del Río y en 1520 a dos mil pasos de Fuente Obejuna se construyó el convento de Nuestra Señora de la Esperanza.

Todos lo hicieron extramuros de las poblaciones, cuando no alejados de sus núcleos urbanos, y se sitúan en la falda de Sierra Morena, en el límite de Andalucía y los territorios de las órdenes militares, en la periferia urbana y regional. En numerosos casos son apoyados, fundados o dotados por la nobleza cordobesa y, especialmente, por personas vinculadas de alguna manera a la Orden de Santiago. Teresa Enríquez colabora en Los Ángeles de Hornachuelos y en San Jerónimo de Cazalla; Enrique Enríquez, comendador mayor de la provincia de León de la Orden de Santiago, en Guadalcanal; Juana de Cárdenas, hija del maestre Alonso de Cárdenas, en N.S. de la Esperanza en Fuente Obejuna. Los señores y condes de Palma ayudan a los conventos de Palma, Gonzalo Messía hace lo propio en San Alberto de Santa Eufemia y el Gran Capitán en N.S. del Socorro de Pedroches. Los vecinos son protagonistas en San Antonio de Chillón y Pedroches. Completan la relación de conventos pertenecientes a la provincia de los Ángeles en Andalucía los de San Francisco de la Columna de Belalcázar, que se une en 1493, San Francisco de Constantina y San Francisco del Monte de Villaverde del Río, los cuales pasaron a la Custodia en 1495.

Tras este proceso de siglos cualquier ciudad de Andalucía es un modelo de urbe conventual donde la propia cerca de la muralla, si cerrara sus puertas, sería un gran convento, verdadera imagen de la Jerusalén Celeste, la Ciudad de Dios en la tierra ${ }^{101}$.

\section{REFLEXIONES FINALES}

Los conventos franciscanos de los siglos XIII y XIV responden a las necesidades repobladoras de la monarquía y no a los estímulos de la sociedad urbana andaluza. Son fundaciones reales, monopolísticas y veteranas, llevadas a cabo en las grandes ciudades que articulan el control del espacio en el Valle del Guadalquivir. La intención es dotar de servicios a los pobladores que se pretenden asentar en los centros urbanos. Es por ello que se fundan conventos en las cabeceras de los obispados (Baeza, Jaén, Córdoba, Sevilla,

${ }^{101}$ Sobre la creación de la ciudad conventual y la imagen de la Jerusalén Celeste, Guidoni 1992. Para la configuración sacra de ciudades como Granada, Henares 2001. Para Córdoba, Olmedo 2012. Para Sevilla, Miura 1998. Un magnífico trabajo referido a Jaén el de Serrano 2009. 
Algeciras) o en los grandes núcleos de defensa (Úbeda y Jerez de la Frontera), aunque algunos de ellos fracasan (Algeciras) o son lentos o tardíos en sus consolidación (Jaén, Úbeda y Baeza). Se trata de ratificar el papel central de los núcleos urbanos conquistados mediante la creación de conventos en los lugares cercanos a las murallas, intramuros o extramuros, dotados de amplios espacios vacíos o incultos a su alrededor, lo cual acaba conformándose como una segunda muralla dotada de un nítido y claro valor simbólico mental ${ }^{102}$.

La consolidación de la población andaluza y el enraizamiento de la misma a un espacio a lo largo del siglo XIV, hace aumentar el número de conventos franciscanos en ciudades, villas y lugares. Tal dispersión, que se produce en el último cuarto de la decimocuarta centuria, es el resultado de un mayor arraigo de la población pero también de la temprana salida de la crisis y del desarrollo del proceso autogenético reformador. Sin embargo, la fase de creación y establecimiento de institutos franciscanos no es indicador del ciclo natural de vinculación de la sociedad urbana y el movimiento mendicante, pues el mismo se articula en procesos de reforma que se enlazaron con el eremitismo y, por ende, a la búsqueda del desierto y el retiro de lo urbano. Algunos intentos permiten localizar franciscanos en el arco periurbano externo a las murallas, pero la norma es la búsqueda de pequeñas poblaciones y, aun así, alejados de su caserío. Tan sólo excepcionalmente buscarán la Banda Morisca (Utrera y Marchena) ocupando lugares seguros en la retaguardia.

Tras 1430 los esfuerzos fundadores franciscanos se centrarán en las ciudades medias y en las cabeceras señoriales. La conquista de Antequera en 1410 redujo la presión militar en las agro-ciudades fronterizas, al tiempo que el fracaso de la reforma eremítica empujó al enjambre de conventículos y oratorios franciscanos a trasladarse al interior de las poblaciones. La proliferación de conventos, aún con una dispar distribución, se vio favorecida desde mediados del siglo XV por una próspera economía agraria y el poder sobre los concejos de realengo de la oligarquía nobiliaria y concejil. Este traslado al interior de las ciudades nos habla de la conquista social, moral y financiera de los franciscanos del conjunto social y del afianzamiento de las relaciones ciudad-convento que se manifiesta tanto en la ubicación de los establecimientos franciscanos como en las funciones que los frailes menores desarrollan como agentes urbanos e, incluso, concejiles.

La consolidación del dominio cristiano sobre el territorio andaluz en el siglo XVI tras la conquista del reino de Granada tendrá su máxima expresión en la fundación de conventos franciscanos en las principales cabeceras

\footnotetext{
${ }^{102}$ Puede servir de ejemplo de la presencia de los elementos religiosos en la repoblación los diversos apartados de la obra Sánchez 2000.
} 
y concejos del reino. Se trata de un traslado de comportamientos y funciones desde los siglos XIII y XIV a fines del XV. Las fundaciones granadinas son por ello reales, monopolísticas y veteranas, al tiempo que agentes cristianizadores de los recintos urbanos con un cercano pasado islámico.

Por otro lado, el desarrollo económico y social de Andalucía, vinculado a la puesta en explotación de la totalidad de la región (especialmente de la extensa y señorializada Banda Morisca tras la conquista del reino de Granada) y al progreso del comercio atlántico, va a provocar una proliferación de manifestaciones físicas de este poder (económico, social y militar) y del triunfo de la ortodoxia, que se concretan en conventos distribuidos por la totalidad de la región pero especialmente por la antes insegura frontera, ya fuera esta terrestre o marítima, y en cada localidad por el entramado urbano, colonizando los espacios extramuros de unas localidades que crecerán fagocitando en el caserío las antiguas ermitas, ahora conventos franciscanos. Esta eclosión de fundaciones franciscanas en los territorios limítrofes con el reino de Granada no afectó a las tierras bajo el señorío jurisdiccional o antiguo señorío de las órdenes militares.

La geografía franciscana andaluza se cierra con la multiplicación de eremitorios dependientes de la provincia de los Ángeles en el arco de Sierra Morena (desde Cazalla a Santa Eufemia y Andújar), que se convierte en la última zona desértica donde los reformadores encuentran el yermo que les permite desarrollar su visión del franciscanimo reformado.

\section{BIBLIOGRAFÍA CITADA}

Alijo Hidalgo, Francisco (1983), Antequera y su Tierra (1410-1510). Libro de Repartimientos, Málaga, Editorial Arguval.

Almansa Moreno, José Manuel (2005), El convento de San Francisco de Úbe$d a$, "Boletín del Instituto de Estudios Giennenses" 191,pp. 187-222.

Álvarez Rodríguez, Alicia (2014), Órdenes mendicantes y espacio urbano: los conventos de franciscanos y dominicos en Zamora, Toro y Benavente en la baja Edad Media, en Paisagens e Poderes no Medievo Ibérico. Actas do I Encontro Ibérico de Jovens Investigadores em Estudos Medievais, Arqueologia, História e Património, Braga, Centro de Investigação Transdisciplinar "Cultura, Espaço e Memória" - Universidade do Minho, pp. 274-291.

Bériou, Nicole (2009), De l'histoire des ordres à l'histoire urbaine. Moines et religieux dans la ville (XII $-X V^{e}$ siècle), en Moines et religieux dans la ville (XII ${ }^{e}-X V^{e}$ siècle), Toulouse, Éd. Privat, pp. 13-29 (Cahiers de Fanjeaux; 44). 
Caby, Cécile (éd.) (2012), Espaces monastiques et espaces urbains de l'Antiquité tardive à la fin du Moyen Âge, "Mélanges de l'École française de Rome. Moyen Âge"124/1. http://journals.openedition. $\mathrm{org} / \mathrm{mefrm} / 94$ [consulta: 18/03/2018].

Capel, Horacio (1973), Percepción del medio y comportamiento geográfico, "Revista de geografía" 7, pp. 58-150.

Carriazo Rubio, Juan Luis (2004), Los testamentos de la Casa de Arcos (1374-1530), Sevilla, Diputación Provincial de Sevilla.

Carrillo Calderero, Alicia (2006), Revisión de la Crónica del Padre Guadalupe: los conventos masculinos de la provincia de los Ángeles en Córdoba, en El franciscanismo en Andalucía: la orden tercera seglar. Conferencias del XI Curso de Verano, Córdoba, Obra Social y Cultural CajaSur, pp. 43-68.

Castillo Utrilla, María José del (1988), El convento de San Francisco, Casa Grande de Sevilla, Sevilla, Diputación Provincial de Sevilla.

Charlo Brea, Luis; Piqueras García, María Belén (2007), Bulas fundacionales de la Diócesis de Cádiz(III). La creación de la diócesis de Algeciras, "Historia, Instituciones, Documentos" 34, pp. 57-76.

Choay, Françoise (1972), Sémiologie et urbanisme, en Le sens de la ville, París, Seuil, pp. 11-30.

Cuadrado Sánchez, Marta (1996), El nuevo marco socioespacial: emplazamiento de los conventos mendicantes en el plano urbano, en VI Semana de Estudios Medievales, Nájera, 31 de julio al 4 de agosto de 1995, Logroño, Instituto de Estudios Riojanos, pp. 101-109.

Cuevas Velázquez-Gaztelu, Jesús de las; Cuevas Velázquez-Gaztelu, José de las (1985), Arcos de la Frontera, Cádiz, Diputación Provincial.

Escribano Castilla, Ángel (1982), Fundaciones franciscanas en la Córdoba bajomedieval, en Andalucía Medieval. Actas I Coloquio Historia de Andalucía, Córdoba, Monte de Piedad y Caja de Ahorros de Córdoba, pp. 331-351.

Eubel, Conrado (1898-1907), Bullarium Franciscanum, V, VI y VII, Roma, Tipografía Vaticana.

Feria Toribio, José María; Miura Andrades, José María; Ruiz Recco, Javier (2002), Tipología de redes de centros históricos de Andalucía, Sevi1la, Consejería de Obras Públicas y Transportes, Junta de Andalucía.

Fernández, José María (1943), Las iglesias de Antequera, Málaga, Centro de Estudios Andaluces.

Frochoso Sánchez, Rafael (2010), Los conventos de San Zoilo Armilatense y San Francisco del Monte en Adamúz (Córdoba), "Boletín de la Real Academia de Córdoba de Ciencias, Bellas Letras y Nobles Artes" 158-159, pp. 177-190. 
Galera Rey, Pedro Antonio (1999), El convento de San Francisco de Jaén, en El franciscanismo en Andalucía: conferencias del III Curso de Verano San Francisco en la cultura y en la historia del arte andaluz, Córdoba, CajaSur - Asociación hispánica de estudios franciscanos, pp. 125-136.

García Fernández, Manuel (1988), Algeciras, 1344-1369, "Estudios de Historia y Arqueología Medievales" 7-8, pp. 59-76.

García Oro, José (1988), San Francisco de Asís en la España Medieval, Madrid, CSIC - Liceo Franciscano.

García Oro, José (1980), Conventualismo y observancia, en Historia de la Iglesia en España, III-1: La Iglesia en la España de los siglos XV y XVI, Madrid, BAC, pp. 211-349.

García Torralbo, María Cruz (2000), Evolución del espacio franciscano en Baeza y sus implicaciones en la ciudad, en El franciscanismo en Andalucía: conferencias del IV Curso de Verano San Francisco en la cultura andaluza e hispanoamericana, Córdoba, Obra Social y Cultural CajaSur, pp. 27-36.

Gilomen, Hans-Jörg (1995), Stadtmauern und Bettelorden, en Stadtmauern und Landmauern, Zurich, VDF Hochschulverlag AG an der ETH Zürich, pp. 45-62.

Gonzaga, Francisco de (1587), De Origine Seraphicae Religionis Franciscanae eiusque Progressibus, Roma, Ex Typographia Dominici Basæ.

González Gómez, Antonio (1977), Moguer en la Baja Edad Media (1248-1538), Huelva, Diputación de Huelva.

González Jiménez, Manuel (1985), Andalucía Bética, en Organización social del espacio en la España medieval. La Corona de Castilla en los siglos VIII a XV, Madrid, Ariel, pp. 163-194.

González Jiménez, Manuel (1988), En torno a los orígenes de Andalucía, Sevilla, Universidad de Sevilla.

González Jiménez, Manuel (ed.) (1991), Diplomatario andaluz de Alfonso X, Sevilla, El Monte, Caja de Huelva y Sevilla.

Graña Cid, María del Mar (1993), Religiosos en via. Franciscanos y caminos en Castilla la Nueva (1215-1250), en I Congreso Internacional de Caminería Hispánica, Guadalajara, AACHE Editores, vol. II, pp. 127-148.

Graña Cid, María del Mar (1995), Fundaciones franciscanas en el reino de Granada (1492-1550), "Isidorianum" 4-8, pp. 195-214.

Graña Cid, María del Mar (1997), Franciscanos y franciscanas en el reino de Granada: panorama fundacional (ca. 1485-1550), en El franciscanismo en Andalucía: conferencias del I Curso de verano sobre el 
franciscanismo en Andalucía, Córdoba, Obra Social y Cultural CajaSur, pp. 105-120.

Guadalupe, Andrés de (1662), Historia de la Santa Provincia de los Angeles, de la Regular Observancia y Orden de Nuestro Seráfico Padre Francisco, Madrid, Mateo Fernández.

Guidoni, Enrico (1977), Città e ordini mendicanti. Il ruolo dei conventi nella crescita e nella progettazione urbana del XIII e XIV secolo, "Quaderni Medievali" 4, pp. 69-106.

Guidoni, Enrico (1992), L'arte di progettare le città. Italia e Mediterraneo dal medioevo al settecento, Roma, Kappa.

Henares Cuéllar, Ignacio Luis (2001), Ciudad y arquitectura: el conjunto catedralicio de Granada en la Edad Moderna, en Castillo Oreja, Miguel Ángel (coord.), Las catedrales españolas en la Edad Moderna: aproximación a un nuevo concepto del espacio sagrado, Madrid, Fundación BBVA, pp. 85-128

Hernández González, Salvador (2006), La orden tercera en la provincia franciscana de Los Ángeles, en El franciscanismo en Andalucía: la orden tercera seglar. Conferencias del XI Curso de Verano, Córdoba, Obra Social y Cultural CajaSur, pp. 295-304.

Hernández Díaz, José; Sancho Corbacho, Antonio; Collantes de Terán, Francisco (1939), Catálogo arqueológico y artístico de la provincia de Sevilla, Sevilla, Diputación Provincial de Sevilla.

Juliá Gómez, José (1972), El Convento de San Francisco de Santisteban del Puerto, "Boletín del Instituto de Estudios Giennenses" 70-71, pp. 37-64.

Le Goff, Jacques (1968), Apostolat mendiant et fait urbain dans la France médiévale: L'implantation des ordres mendiants. Programme-questionnaire pour une enquête, "Annales. Economies, Sociétés, Civilisations" 23, pp. 337-343.

Le Goff, Jacques (1970) Ordres mendiants et urbanisation dans la France médiévale. Etat de l'enquête, "Annales. Economies, Sociétés, Civilisations" 25, pp. 924-946.

López, Tomás (1989), Diccionario Geográfico de Andalucía: Sevilla, Sevilla, Editorial Don Quijote.

López Ontiveros, Antonio (1994), La agrociudad andaluza: caracterización, estructura y problemática, "Revista de estudios regionales" 39, pp. 59-92.

Mansilla Lasoli, Demetrio (1957), La creación del obispado de Cádiz y Algeciras, "Hispania Sacra" 10, pp. 243-271.

Marín Cobos, Almudena (2013) Convento Casa Grande de San Francisco, en Peñalver Gómez, Eduardo (coord.), Bibliotecas en la Biblioteca de 
la Universidad de Sevilla: exposición virtual 2013, Sevilla, Universidad de Sevilla, pp. 158-164.

Medianero Hernández José María (1997), El convento Casa Grande de San Francisco en Sevilla y su repercusión en el ambiente cultural y artístico bajomedieval de la ciudad, en El franciscanismo en Andalucía: conferencias del I Curso de Verano sobre el franciscanismo en Andalucía, Córdoba, Obra Social y Cultural CajaSur, pp. 121-130.

Mesa Ginete, Francisco de (1888), Historia sagrada y política de la muy noble y muy leal de Tarteso, Turdeto, Asta Regia, Asido Cesariana, Asidonia Gera, Jerez Sidonia hoy Jerez de la Frontera, Jerez, [s.n.].

Miura Andrades, José María (1994), Las primeras noticias de la presencia franciscana en Alcalá de Guadaíra, "Qalat Chábir (Revista de Humanidades)" 2, pp. 3-7.

Miura Andrades, José María (1998), Frailes, monjas y conventos. Las órdenes mendicantes y la sociedad sevillana bajomedieval, Sevilla, Diputación Provincial de Sevilla.

Miura Andrades, José María (2014a), Las reformas tempranas del franciscanismo castellano: eremitas, conventos y obediencias en la Andalucía de los siglos XIV y XV, "Semata: Ciencias sociais e humanidades" 26, pp. 111-128.

Miura Andrades, José María (2014b), Monjes, frailes, monjas y otras formas de vida religiosa en Jerez de la Frontera a fines de la Edad Media, en Barea Rodríguez, Manuel Antonio (coord.); Romero Bejarano, Manuel (coord.); Sánchez Herrero, José (dir.); González Jiménez, Manuel (dir.), 750 aniversario de la incorporación de Jerez a la Corona de Castilla: 1264-2014, Jerez, Ayuntamiento de Jerez, pp. 559-575.

Moreno Ollero, Antonio (1984), Sanlúcar en la Baja Edad Media, Cádiz, Diputación de Cádiz.

Nieto Soria, José Manuel (1988), Fundamentos ideológicos del poder real en Castilla (Siglos XIII-XVI), Madrid, editorial Universidad Complutense de Madrid.

Olmedo Sánchez, Yolanda Victoria (2012), De la ciudad conventual a la ciudad burguesa: las órdenes religiosas en la evolución urbana de Córdoba, "Hispania Sacra" 64/129, pp. 29-66.

Ortega, Ángel (1915), Las Casas de Estudio de la Provincia de Andalucía, [Separata y edición aparte de] Madrid, Archivo Ibero Americano.

Ortega, Ángel (1986), La Rábida. Historia Documental y Crítica, Huelva, Diputación Provincial de Huelva.

Palenzuela Domínguez, Natalia (1986), Las Actas Capitulares del Concejo de Sevilla (1435-1447), Sevilla, Departamento de Historia Medieval y Ciencias y Técnicas Historiográficas (memoria de licenciatura inédita). 
Peláez del Rosal, Manuel (2003), Nuevos datos históricos de San Francisco de Priego de Córdoba, en El franciscanismo en Andalucía: conferencias del VII Curso de Verano el arte franciscano en las catedrales andaluzas, Córdoba, Obra Social y Cultural CajaSur, pp. 603-606.

Recio Veganzones, Alejandro (1999), Primeros franciscanos y clarisas en las fronteras de Jaén y Córdoba: sus protomártires e iconografía en la evocación martirial de su V y VI Centenario, en El franciscanismo en Andalucía: conferencias del III Curso de Verano San Francisco en la cultura andaluza e hispanoamericana, Córdoba, Obra Social y Cultural CajaSur, pp. 495-534.

Rodríguez Becerra, Salvador; Hernández González, Salvador (2009), Los conventos en la conformación de las ciudades medias andaluzas, "Zainak. Cuadernos de Antropología-Etnografía” 31, pp. 467-501.

Rubio, Germán (1953), La custodia franciscana de Sevilla. Ensayo histórico sobre sus orígenes, progresos y vicisitudes, Sevilla, editorial San Antonio.

Rucquoi, Adeline, (1996), Los franciscanos en el reino de Castilla, en VI Semana de Estudios Medievales, Nájera, 31 de julio al 4 de agosto de 1995, Logroño, Instituto de Estudios Riojanos, pp. 65-86.

Santiago Reyes, Yolanda (1999), Fray de la Puebla y las fundaciones conventuales de la provincia de los Ángeles, en El franciscanismo en Andalucía: conferencias del III Curso de Verano San Francisco en la cultura andaluza e hispanoamericana, Córdoba, Obra Social y Cultural CajaSur, pp. 549-552.

Sánchez Herrero, José (1981), Cádiz. La ciudad medieval y cristiana. 12601525, Córdoba, Caja de Ahorros de Córdoba.

Sánchez Herrero, José (2000), La organización de la diócesis de Sevilla, en González Jiménez, Manuel (coord.), Sevilla 1248: Congreso Internacional Conmemorativo del 750 Aniversario de la Conquista de la Ciudad de Sevilla por Fernando III, Rey de Castilla y León, Sevilla, Ayuntamiento de Sevilla - Madrid, Fundación Ramón Areces, pp. 337-356.

Sanz Sancho, Iluminado (1989), La iglesia y el obispado de Córdoba en la Baja Edad Media (1236-1426), Madrid, Universidad Complutense (tesis doctoral).

Sancho de Sopranis, Hipólito (1945), San Francisco el Real de Jerez en el siglo XV, "Archivo Ibero-Americano" 5, pp. 366-404 y pp. 481-527.

Serrano Estrella, Felipe (2006), Expansión e influencia del franciscanismo en el reino de Jaén, en El franciscanismo en Andalucía: la orden tercera seglar. Conferencias del XI Curso de Verano, Córdoba, Obra Social y Cultural Cajasur, pp. 481-502. 
Serrano Estrella, Felipe (2009), Órdenes mendicantes y ciudad. El patrimonio conventual de Jaén en la Edad Moderna, Granada, Editorial de la Universidad de Granada,

Torres, Alonso de (1683), Chrónica de la Santa Provincia de Granada, de la Regvlar Observancia de Nuestro Seráfico Padre San Francisco, Madrid, [s.n.].

Viallet, Ludovic (2013), Les ordres mendiants dans la ville médiévale (v. 1230-v. 1350): réflexions introductives, en Carraz, Damien (dir.), Les ordres militaires dans la ville médiévale (1100-1350), ClermontFerrand, Presses Universitaires Blaise-Pascal, pp. 57-75.

Vilaplana, María Asunción (1975), La colección diplomática de Santa Clara de Moguer: 1280-1483, Sevilla, Universidad de Sevilla.

Waddingo, Lucas (1886-1933), Annales Minorum, Roma, Quarachi.

Fecha de recepción del artículo: octubre 2017

Fecha de aceptación y versión final: marzo 2018 